\title{
ORAI1 mutations with distinct channel gating defects in tubular
}

\author{
aggregate myopathy
}

Johann Böhm ${ }^{1,2,3,4,5^{*}}$, Monica Bulla ${ }^{6^{*}}$, Jill E. Urquhart ${ }^{7,8}$, Edoardo Malfatti ${ }^{9,10}$, Simon G. Williams $^{7}$, James O'Sullivan ${ }^{7,8}$, Anastazja Szlauer $^{6}$, Catherine Koch ${ }^{1,2,3,4,5}$, Giovanni Baranello $^{11}$, Marina Mora ${ }^{12}$, Michela Ripolone ${ }^{13}$, Raffaella Violano ${ }^{13}$, Maurizio Moggio $^{13}$, Helen Kingston ${ }^{7}$, Timothy Dawson ${ }^{14}$, Christian G. DeGoede ${ }^{15}$, John Nixon ${ }^{16}$, Anne Boland ${ }^{17}$, Jean-François Deleuze ${ }^{17}$, Norma Romero ${ }^{9,10}$, William G. Newman ${ }^{7,8}$, Nicolas Demaurex ${ }^{6}$, Jocelyn Laporte ${ }^{1,2,3,4,5}$

${ }^{1}$ Departement of Translational Medicine and Neurogenetics, IGBMC (Institut de Génétique et de Biologie Moléculaire et Cellulaire), 67404 Illkirch, France

${ }^{2}$ Inserm, U964, 67404 Illkirch, France

${ }^{3}$ CNRS, UMR7104, 67404 Illkirch, France

${ }^{4}$ Fédération de Médecine Translationnelle, University of Strasbourg, 67404 Illkirch, France

${ }^{5}$ Collège de France, Chaire de Génétique Humaine, 67404 Illkirch, France

${ }^{6}$ Department of Cell Physiology and Metabolism, University of Geneva, 1211 Geneva, Switzerland

${ }^{7}$ Manchester Centre for Genomic Medicine, St. Mary's Hospital, Manchester M13 9WL, UK

${ }^{8}$ Manchester Centre for Genomic Medicine, University of Manchester, Manchester M13

9WL, UK

This article has been accepted for publication and undergone full peer review but has not been through the copyediting, typesetting, pagination and proofreading process, which may lead to differences between this version and the Version of Record. Please cite this article as doi: 10.1002/humu.23172.

This article is protected by copyright. All rights reserved. 
${ }^{9}$ Centre de Référence de Pathologie Neuromusculaire Paris-Est, Groupe Hospitalier PitiéSalpêtrière, 75013 Paris, France

${ }^{10}$ Institut de Myologie, GHU La Pitie-Salpetriere, 75013 Paris, France

${ }^{11}$ Developmental Neurology Unit, Fondazione IRCCS Istituto Neurologico C. Besta, 20133 Milano, Italy

${ }^{12}$ Neuromuscular Diseases and Neuroimmunology Unit, Fondazione IRCCS Istituto Neurologico C. Besta, 20133 Milano, Italy

${ }^{13}$ Neuromuscular and Rare Diseases Unit, Department of Neuroscience, Fondazione IRCCS Ca' Granda, Ospedale Maggiore Policlinico, 20122 Milan, Italy

${ }^{14}$ Department of Pathology, Royal Preston Hospital, Preston PR2 9H7, UK

${ }^{15}$ Department of Paediatric Neurology, Royal Preston Hospital, Preston PR2 9HT, UK

${ }^{16}$ Department of Neurology, Royal Preston Hospital, Preston PR2 9H7, UK

${ }^{17}$ Centre National de Génotypage, Institut de Génomique, CEA, 91057 Evry, France

*These authors contributed equally

Correspondence: Jocelyn Laporte (jocelyn@igbmc.fr) Johann Böhm (johann@igbmc.fr)

Tel.: +33 (0)3 886534 12, Fax: +33 (0)388653201

Grant sponsor: This work was supported by grants from Institut National de la Santé et de la Recherche Médicale (INSERM), Centre National de la Recherche Scientifique (CNRS), University of Strasbourg, Collège de France, France Génomique as national infrastructure grant funded as part of the Investissements d'Avenir program managed by Agence Nationale 
de la Recherche [ANR-10-INBS-09], Fondation Maladies Rares within the frame of the "Myocapture" sequencing project, Association Française contre les Myopathies [AFM 17088], Muscular Dystrophy Association [MDA 294660], and the Swiss National Science Foundation [31003A-149566 to ND, 323530_158118 to MB].

\begin{abstract}
Calcium $\left(\mathrm{Ca}^{2+}\right)$ is a physiological key factor, and the precise modulation of free cytosolic $\mathrm{Ca}^{2+}$ levels regulates multiple cellular functions. Store-operated $\mathrm{Ca}^{2+}$ entry (SOCE) is a major mechanism controlling $\mathrm{Ca}^{2+}$ homeostasis, and is mediated by the concerted activity of the $\mathrm{Ca}^{2+}$ sensor STIM1 and the $\mathrm{Ca}^{2+}$ channel ORAI1. Dominant gain-of-function mutations in STIM1 or ORAI1 cause tubular aggregate myopathy (TAM) or Stormorken syndrome, while recessive loss-of-function mutations are associated with immunodeficiency. Here we report the identification and functional characterization of novel ORAII mutations in TAM patients. We assess basal activity and SOCE of the mutant ORAI1 channels, and we demonstrate that the G98S and V107M mutations generate constitutively permeable ORAI channels, while T184M alters the channel permeability only in the presence of STIM1. These data indicate a mutation-dependent pathomechanism and a genotype/phenotype correlation, as the ORAII mutations associated with the most severe symptoms induce the strongest functional cellular effect. Examination of the non-muscle features of our patients strongly suggest that TAM and Stormorken syndrome are spectra of the same disease. Overall, our results emphasize the importance of SOCE in skeletal muscle physiology, and provide new insights in the pathomechanisms involving aberrant $\mathrm{Ca}^{2+}$ homeostasis and leading to muscle dysfunction.
\end{abstract}




\section{KEYWORDS}

Tubular aggregate myopathy, Stormorken syndrome, ORAI1, calcium, SOCE, STIM1

\section{INTRODUCTION}

Skeletal muscle physiology directly depends on changes in free cytosolic calcium $\left(\mathrm{Ca}^{2+}\right)$ levels, and small disturbances in $\mathrm{Ca}^{2+}$ homeostasis can severely impact on muscle contraction, differentiation, or gene transcription. A major mechanism controlling $\mathrm{Ca}^{2+}$ homeostasis is store-operated $\mathrm{Ca}^{2+}$ entry (SOCE), which is triggered by $\mathrm{Ca}^{2+}$ store depletion of the endoplasmic/sarcoplasmic reticulum (ER/SR), and results in extracellular $\mathrm{Ca}^{2+}$ influx through $\mathrm{Ca}^{2+}$ release-activated $\mathrm{Ca}^{2+}(\mathrm{CRAC})$ channels as ORAI1 (MIM\# 610277). This highly $\mathrm{Ca}^{2+}$-selective plasma membrane channel is composed of tetramers or hexamers forming three concentric rings around the central pore (Hou, et al. 2012; Thompson and Shuttleworth 2013; Cai, et al. 2016). Each ORAI1 subunit is composed of 4 alpha-helical transmembrane domains (M1 to M4) linked by two external (I and III) and one internal (II) loop, with the $\mathrm{N}$ - and $\mathrm{C}$-termini facing the cytosol. The M1 transmembrane domain constitutes the $\sim 55 \AA$ long channel pore with an acidic glutamate ring at position E106 forming the selectivity filter and, together with negative residues in the first external loop, conferring high selectivity for $\mathrm{Ca}^{2+}$ ions (Vig, et al. 2006; Zhou, et al. 2010; McNally, et al. 2012; Frischauf, et al. 2015). The central segment of the pore contains a rigid hydrophobic 
section responsible for the low channel conductance, a gating hinge controlling pore opening, and a basal component potentially avoiding backward $\mathrm{Ca}^{2+}$ efflux from the cytoplasm (Zhang, et al. 2011).

Channel opening is mediated through the interaction of the cytoplasmic $\mathrm{N}$ - and C-termini of the ORAI1 subunits with STIM1 (MIM\# 605921), a transmembrane protein in the ER/SR able to sense luminal $\mathrm{Ca}^{2+}$ (Muik, et al. 2008; Navarro-Borelly, et al. 2008; Zheng, et al. 2013). $\mathrm{Ca}^{2+}$ store depletion induces a conformational change resulting in oligomerization and cytosolic extension of the STIM1 molecules. The exposure of lipid-binding and channel activating domains (CAD) promotes the accumulation of the STIM1 oligomers at junctional ER/SR structures near the plasma membrane, where they trap and gate the ORAI channels (Luik, et al. 2006; Stathopulos, et al. 2006; Park, et al. 2009).

We previously identified STIM1 gain-of-function mutations as genetic cause of autosomal dominant tubular aggregate myopathy (TAM, MIM\# 160565) (Bohm, et al. 2013). TAM mostly involves elevated creatine kinase (CK) levels and slowly progressive muscle weakness predominantly affecting the proximal muscles of the lower limbs, but also myalgia, cramps, and asymptomatic CK elevation have been described (Bohm, et al. 2013; Bohm, et al. 2014; Hedberg, et al. 2014; Walter, et al. 2015). Muscle biopsies from patients with TAM typically show regular arrays of 70-200 $\mathrm{nm}$ long membrane tubules as the main histopathological hallmark (Chevessier, et al. 2005). Tubular aggregates can also arise as secondary features in various inherited and acquired muscle disorders, and accumulate in normal muscle with age (Boncompagni, et al. 2012). All TAM mutations affect highly conserved amino acids in the $\mathrm{Ca}^{2+}$-sensing EF hand domains of STIM1. The only cytosolic STIM1 mutation R304W has been associated with Stormorken syndrome (MIM\# 185070), a multisystemic disorder involving tubular aggregate, elevated CK levels, miosis, 
thrombocytopenia, ichthyosis, asplenia, dyslexia, and short stature (Misceo, et al. 2014; Morin, et al. 2014; Nesin, et al. 2014). Mutations in STIM1 causing either TAM or Stormorken syndrome were both shown to induce constitutive STIM1 oligomerization, CRAC channel activation and $\mathrm{Ca}^{2+}$ influx in the absence of store depletion (Bohm, et al. 2013; Bohm, et al. 2014; Misceo, et al. 2014; Nesin, et al. 2014). Recently, three gain-offunction mutations causing TAM or a Stormorken-like syndrome were also described in ORAI1 (Nesin, et al. 2014; Endo, et al. 2015). These mutations did not alter ORAI1 localization at the plasma membrane, but resulted in increased SOCE and diminished $\mathrm{Ca}^{2+}$ dependent channel inactivation (CDI).

This study reports the identification of three ORAII gain-of-function mutations (two in the channel pore and one in M3) in patients with TAM with or without isolated characteristics of Stormorken syndrome. Based on clinical, histological, genetic, and functional data, we establish a genotype/phenotype correlation and conclude that TAM and Stormorken syndrome clinically overlap, and have to be considered as spectra of the same disease. We provide the functional evidence that mutations in the first transmembrane domain induce a STIM1-independent permeable $\mathrm{Ca}^{2+}$ channel resulting in a more severe phenotype, while the mutation in the third transmembrane domain requires activation through STIM1 to generate an excessive $\mathrm{Ca}^{2+}$ influx and causes a milder phenotype, suggesting that the ORAII mutations involve different pathological mechanisms.

\section{MATERIALS AND METHODS}

\section{Patients}


Sample collection was performed with informed consent from the patients according to the declaration of Helsinki and experimentation was performed following institutional IRBaccepted protocols and the Comite de Protection des Personnes Est IV (DC-2012-1693). Patients were from Honduras (Family 1), the United Kingdom (Family 2), and Italy (Family $3)$.

\section{Sequencing and segregation analysis}

Genomic DNA was prepared from peripheral blood by routine procedures and STIMI mutations were excluded by Sanger sequencing. Whole exome sequencing was carried out for patient 11200 from Family 1, and for patients II.1, II.3, and IV.1 from Family 2 using the SureSelect Human All Exon Kit v4 (Agilent, Santa Clara, USA) and the Illumina HiSeq 2000 or 2500 systems (San Diego, USA). Sequence data were aligned to the GRCh37/hg19 reference genome using the Burrows-Wheeler aligner software (http://biobwa.sourceforge.net), and variant calling was performed with SAMtools (Li, et al. 2009) or the UnifiedGenotyper (https://www.broadinstitute.org/gatk). Following databases were used for SNP annotation and filtering: Exome Variant Server (http://evs.gs.washington.edu/EVS/), $\begin{array}{llll}\text { ExAC } & \text { Browser } & \text { (http://exac.broadinstitute.org/), }\end{array}$ (http://www.ncbi.nlm.nih.gov/projects/SNP/), 1000 genomes (http://www.1000genomes.org/), as well as the in-house exome databases in Illkirch and Manchester. Impacts of variations were predicted using Alamut v.2.5 (http://www.interactive-biosoftware.com).

For patient 5510 from Family 3, direct Sanger-sequenced for both coding exons of ORAII and the adjacent splice-relevant regions was performed. Segregation analyses for Families 1 and 2 were also performed by Sanger sequencing. The ORAII mutations were numbered according to GenBank NM_032790.3 and NP_116179.2. Nucleotide position reflects cDNA 
numbering with +1 corresponding to the A of the ATG translation initiation codon. All identified mutations have been submitted to the LOVD database

(http://www.lovd.nl/ORAI1).

\section{Histology and electron microscopy}

For histology, transverse sections $(10 \mu \mathrm{m})$ of the muscle biopsies were stained with modified Gomori Trichrome, NADH tetrazolium reductase (NADH-TR) and Succinic dehydrogenase (SDH) and assessed for fiber morphology, fiber type distribution, and accumulations/infiltrations.

For electron microscopy, muscle sections were fixed in $2.5 \%$ paraformaldehyde, $2.5 \%$ glutaraldehyde, and $50 \mathrm{mM} \mathrm{CaCl} 2$ in $0.1 \mathrm{M}$ cacodylate buffer (pH 7.4). Samples were postfixed with $2 \% \mathrm{OsO}_{4}, 0.8 \% \mathrm{~K}_{3} \mathrm{Fe}(\mathrm{CN})_{6}$ in $0.1 \mathrm{M}$ cacodylate buffer $(\mathrm{pH} 7.4)$ for $2 \mathrm{~h}$ at $4{ }^{\circ} \mathrm{C}$ and incubated with $5 \%$ uranyl acetate for $2 \mathrm{~h}$ at $4{ }^{\circ} \mathrm{C}$. Muscles were dehydrated in a graded series of ethanol and embedded in epon resin. Thin sections were examined with an electron microscope (Philips CM120, FEI Company, Hillsboro, USA).

\section{Protein studies}

Immunofluorescence was performed with routine protocols using following antibodies: rabbit anti-Orai1 (Abcam, Paris, France), mouse anti-GOK/Stim1 (BD Biosciences, Franklin Lakes, USA), mouse Anti-Ryanodine receptor Clone 34C Product R-12 (Sigma-Aldrich, Saint Louis, USA), NCL-SERCA2 mouse monoclonal antibody, clone IID8 (Novocastra, Newcastle, UK). Sections were mounted with antifade reagent (Invitrogen, Carlsbad, USA) and viewed using a laser scanning confocal microscope (TCS SP2; Leica Microsystems, Wetzlar, Germany). 


\section{Constructs}

The human ORAI-eGPF and mCherry-STIM1 constructs were kind gifts from Liangyi Chen (Beijing University, China) and Richard S. Lewis (Stanford University, USA). The ORAII point mutations (c.292G>A, c.319G >A, c.551C > T) were introduced by site-directed mutagenesis using the Pfu DNA polymerase (Stratagene, La Jolla, USA). The plasmid carrying an untagged STIM1 was purchased from OriGene (NM_003156; OriGene Technologies, Rockville, USA), and the control vector pEGFP-C1 from Clontech (Palo Alto, CA).

\section{Cells and transfections}

Stim $1^{-/} /$Stim $2^{-/-}$mouse embryonic fibroblasts (MEF-DKO), generated by targeted gene disruption, were a kind gift from Masatsugu Oh-Hora (Tokyo Medical and Dental University, Japan), and HEK-293T cells were purchased from ATCC (CRL-11268; Manassas, USA). MEF-DKO and HEK-293T cells were respectively cultured in DMEM 15140-122 and 31966-021 (Gibco Life Technologies, Carlsbad, USA) supplemented with 10\% fetal bovine serum (10270-106, Gibco Life Technologies), $5 \mu \mathrm{g} / \mathrm{ml}$ streptomycin and 5 units/ml penicillin (15140-122, Gibco Life Technologies), and were maintained at $37{ }^{\circ} \mathrm{C}$ in $5 \% \mathrm{CO}_{2}$. Cells were seeded on poly-L-lysine (P4832; Sigma-Aldrich) coated glass coverslips, and transfected at 50\% confluency with Lipofectamine® 2000 (11668-019; Invitrogen). For coexpression experiments, mCherry-STIM1 and ORAI1-eGFP constructs were transfected in a 3:1 ratio by mass. For cells transfected with the ORAI1-eGFP G98S mutant and the respective controls, low $\mathrm{Ca}^{2+}$ containing medium $\left(0.2 \mathrm{mM} \mathrm{CaCl}_{2}\right)$ was used to prevent $\mathrm{Ca}^{2+}$ toxicity. All subsequent experiments were performed within $24 \mathrm{~h}$ post transfection.

\section{TIRF microscopy}

This article is protected by copyright. All rights reserved. 
To assess the impact of the ORAII mutations on the channel distribution at the plasma membrane (PM), HEK-293T cells were co-transfected with wild type (WT) or mutated ORAI1-eGFP and an untagged STIM1 construct, and cultured overnight in low $\mathrm{Ca}^{2+}$ containing medium complemented with $5 \mu \mathrm{M}$ lanthanum. The TIRF plane was determined according to the PM GFP fluorescence at resting state, and images were collected by a Nikon Eclipse Ti microscope (Tokyo, Japan) equipped with a Perfect Focus System, a 100x 1.49 Oil CFI Apochromat TIRF objective and a cooling EMCCD iXon camera (DU-897E-CS0-\#BV500; Andor Technology Ltd, Belfast, Northern Ireland). Cells were excited with a $488 \mathrm{~nm} 50$ $\mathrm{mW}$ laser and light was collected through the TIRF Quad dichroic beamsplitter 405/488/561/640 and the emission filter FITC 525/50 from Nikon. The experiment was performed at room temperature. Cells were treated with $1 \mu \mathrm{M}$ Thapsigargin (Sigma-Aldrich) to follow the kinetics of ORAI1 clustering at the PM. Live images were acquired with the NIS-Elements AR software V4.30.02 (Nikon), and ORAI1 clusters were quantified and characterized with a granularity detection journal on Metamorph software 7.8.12.0 (Molecular Devices, Sunnyvale, USA) after background subtraction. Regions containing clusters were identified at the end of each experiment and their increasing intensities were plotted over time. The results were normalized as follows: $\mathrm{Fc}_{(\mathrm{t}=\mathrm{n})}=\left(\operatorname{Fcr}_{(\mathrm{t}=\mathrm{n})}-\operatorname{Frr}_{(\mathrm{t}=\mathrm{n})}\right) ; \mathrm{F} / \mathrm{F0} 0_{(\mathrm{t}=\mathrm{n})}$ $=\left(\Sigma \operatorname{Fc}_{(\mathrm{t}=\mathrm{n})} / \mathrm{nb}\right.$. clusters $\left.+\operatorname{Frr}_{(\mathrm{t}=0)}\right) / \operatorname{Frr}_{(\mathrm{t}=0)}$, where $\operatorname{Fc}_{(\mathrm{t}=\mathrm{n})}$ is the fluorescence intensity of a cluster at a given time, $\operatorname{Fcr}_{(t=n)}$ the intensity measured in a region that will contain a cluster following store depletion, and $\operatorname{Frr}_{(\mathrm{t}=\mathrm{n})}$ the intensity of a reference region devoid of clusters throughout the experiment. The average fluorescence intensity of cumulated clusters at the cellular level $\left(\mathrm{F}_{(\mathrm{t}=\mathrm{n})}\right)$ was normalized to the fluorescence of the empty region at the beginning of the experiment $\left(\mathrm{F} 0=\mathrm{Frr}_{(\mathrm{t}=0)}\right)$. The percentage of the PM covered by clusters (density) was determined as the summed area of clusters divided by the total surface of the PM visible in the TIRF plane. 


\section{$\mathrm{Ca}^{2+}$ measurements}

To assess cytosolic $\mathrm{Ca}^{2+}$ levels, cells were loaded at room temperature with $4 \mu \mathrm{M}$ of the $\mathrm{Ca}^{2+}$ sensor Fura-2 AM and $1 \mu$ M Pluronic acid F-127 (F-1201 and P-3000MP; Invitrogen) in 2 or $0.2 \mathrm{mM} \mathrm{CaCl}{ }_{2}$ recording solution. After 30 minutes in the dark, cells were washed and allowed for de-esterification for at least 15 min. Fura-2 ratiometric fluorescence emission was recorded with an Axio Observer microscope (Zeiss, Jena, Germany) equipped with a Lambda DG4 175 watts xenon arc lamp (Sutter Instrument Company, Novato, USA) and a rapidly changing filter wheel (Ludl Electronic Products, München, Germany). Excitation filters 340AF15 and 380AF15 were purchased from Omega Optical (Brattleboro, USA). Exposure time was 500 ms every 3 seconds for each wavelength. Emission was collected through the dichroic/filter couple 415DCLP/510WB40 (Omega Optical), by a 12-bit CCD cooling camera (CoolSnap HQ, Ropper Scientific, Trenton, USA) with a 2x gain and a binning of 4. To measure store-operated $\mathrm{Ca}^{2+}$ entry, $1 \mu \mathrm{M}$ Thapsigargin was used to passively deplete the $\mathrm{Ca}^{2+}$ stores. For $\mathrm{Mn}^{2+}$ quenching experiments, $500 \mu \mathrm{M} \mathrm{Mn}{ }^{2+}$ were added while cells were excited at $360 \mathrm{~nm}$ (360BP10, Omega Optical). Recording solutions contained $140 \mathrm{mM} \mathrm{NaCl}$, $5 \mathrm{mM} \mathrm{KCl}, 1 \mathrm{mM} \mathrm{MgCl} 2,10 \mathrm{mM}$ Hepes, $10 \mathrm{mM} \mathrm{D-(+)-glucose} \mathrm{and} \mathrm{the} \mathrm{indicated} \mathrm{amounts} \mathrm{of}$ $\mathrm{CaCl}_{2}$. The $\mathrm{Ca}^{2+}$-free solution contained $1 \mathrm{mM}$ EGTA instead of $\mathrm{CaCl}_{2}$. The $\mathrm{pH}$ was adjusted to 7.4 at $37{ }^{\circ} \mathrm{C}$ with $\mathrm{NaOH}$. All experiments were achieved at $37{ }^{\circ} \mathrm{C}$ with pre-heated solutions. $\mathrm{Ca}^{2+}$ recordings were acquired and analyzed with the Metafluor 6.3 software (Universal Imaging, West Chester, USA) after background subtraction. For cells coexpressing mCherry-STIM1 and ORAI1-eGFP constructs, only cells with a mCherry/eGFP fluorescence ratio above 1 were analyzed.

\section{Statistics}


GraphPad Prism 6.05 was used for statistical evaluation of the data. Statistical significance was determined by the two-tailed unpaired Student's test with systematic Welch correction for variance.

\section{RESULTS}

\section{Clinical reports}

The patients characterized in this study belong to three unrelated families with a broad range of symptoms and signs with different ages of onset and disease severity, but sharing prominent tubular aggregates on muscle biopsies as the main histopathological hallmark. Patient 11200 (Family 1) is a singleton, Family 2 has an ancestral history of a muscle phenotype segregating as a dominant disease over at least four generations, and Family 3 displays a mother to son disease inheritance (clinical features summarized in Table 1).

Patient 11200 from Family 1 is now 12 years old. Pregnancy, birth and neonatal history were uneventful, although motor milestones were slightly delayed. The patient achieved sitting at the age of 8 months, and independent walking at 24 months. Tip-toe-walking and frequent falls were noticed since age 2, and contractures of elbows and Achilles tendons were diagnosed in the following years. Clinical examination at the age of 10 revealed ichthyosis, stiffness, proximal muscle weakness and reduced tendon reflexes of the lower limbs. The patient was unable to jump, and had a waddling gait. He reported cramps and myalgia, both at rest and after exercise, headaches, and frequent episodes of bleeding from mouth, nose, and bowel. He had anemia but not thrombocytopenia, and blood calcium levels were repeatedly normal or only mildly reduced. Eye examination showed miosis, heart and lung functions were normal, and cognitive assessment showed results within the normal range. CK levels 
were repeatedly elevated, with values up to 2052 U/l. Motor nerve conduction velocities were normal and EMG showed chronic neurogenic abnormalities and mild myopathic changes in the proximal lower limbs. Muscle MRI revealed fibro-fatty replacements in the posterior and medial compartments of the thigh and of the posterior compartment of the calf (Supp. Figure S1). Abdominal ultrasound excluded asplenia/hyposplenia. The parents and the younger sister are healthy.

For Family 2, five affected members underwent regular clinical examinations. They are now between 6 and 47 years old, and pregnancy, birth, and early childhood was normal for all. Slightly delayed motor milestones as well as slight dyslexia were reported for patients IV.1, and IV.2, and might have been overlooked for the older generations. All showed tip-toe walking associated to Achilles tendon contractures by the age of 8 years. Only the youngest patient, now 6 years old, does not show tip-toe walking. The proximal muscle of the lower limbs were predominantly affected, and involved weakness (II.1, III.1, III.2), stiffness (II.1, III.2), cramps (II.1, III.2), and myalgia (II.1, III.1, IV.1, IV.2). All had difficulties running and climbing stairs. Calf hypertrophy was noted for patients III.1 and IV.1. CK levels were elevated for all and ranged between 484 and 1538 U/I. Motor nerve conduction velocity, assessed for patient III.1 was normal, and EMG showed myopathic changes.

Patient 5510 from Family 3 was diagnosed with asymptomatic hyperCKemia through routine blood tests at the age of 56. Medical examination at age 60 revealed mild general muscle weakness, and the patient reported myalgia of the lower limbs and cramps, but motor nerve conduction velocity and EMG did not reveal any abnormalities. The patient also presented with hypereosinophilia resulting from allergic diathesis, pectus excavatum, and arched palate. CK levels were repeatedly elevated and ranged between 400 and $600 \mathrm{U} / \mathrm{I}$, and his mother was also reported to have asymptomatic hyperCKemia. 


\section{Histology and ultrastructural analyses reveal tubular aggregates}

Muscle biopsies from all patients described in this study displayed tubular aggregates appearing on Gomori trichrome and on NADH-TR staining (Figure 1). In agreement with previously described TAM cases, the aggregates are less detectable with SDH, suggesting a reticulum and not a mitochondrial origin (Chevessier, et al. 2005; Bohm, et al. 2013). Aggregates were observed in both fiber types in all analyzed biopsies. Additional observations comprise fiber size variability and internalized nuclei.

Ultrastructural analyses demonstrated that the tubular aggregates are of variable size and consist of single or double-walled membranes of different diameter (Figure 1). Overall, the histological and ultrastructural features of the biopsies were strikingly similar and strongly suggestive of tubular aggregate myopathy.

\section{Exome sequencing identifies mutations in $O R A I I$}

Sanger sequencing of the known TAM gene STIMI did not reveal any putative pathogenic variant in the families described here. We performed exome sequencing for Families 1 and 2, and identified heterozygous missense mutations in ORAIl. Patient 11200 from Family 1 carries the ORAII c.292G>A (p.Gly98Ser) de novo mutation in exon 1, and the affected members of Family 2 harbor the ORAII c.319G >A (p.Val107Met) mutation in exon 2 (Figure 2A). Another missense mutation (c.551C>T; p.Thr184Met) in exon 2 was found by direct ORAII Sanger sequencing of patient 5510 from Family 3. None of the three mutations was found in the available healthy family members and none was listed in the public or internal SNP databases. However, the p.Gly98Ser mutation was previously described in an unrelated Japanese family with TAM involving diffuse muscle weakness, joint contractures, a rigid spine and hypocalcaemia (Endo, et al. 2015). 
All three missense mutations affect highly conserved amino acids in ORAI1 (Figure 2B) The mutations p.Gly98Ser and p.Val107Met affect amino acids in M1, and p.Thr184Met affects an amino acid in M3 (Figure 2C). M1 forms the ion conduction pathway, while M2 and M3 encircle the pore and are surrounded by the M4 outer ring (Hou, et al. 2012; Frischauf, et al. 2015). The residue G98 is located in the rigid section of the channel responsible for ion conduction, and the residue V107 neighbors E106, involved in $\mathrm{Ca}^{2+}$ selectivity.

\section{Tubular aggregates contain STIM1}

To characterize the structure and composition of the tubular aggregates associated with ORAII mutations, we performed immunolocalization experiments on muscle biopsies from patient 11200 (Family 1) and II.1 (Family 2) (Figure 1). We previously showed that tubular aggregates in TAM patients with STIM1 mutations contain various SR proteins as STIM1, the

$\mathrm{Ca}^{2+}$ channel RYR1 (MIM\# 180901), the RYR1-effector triadin (MIM\# 603283), or the $\mathrm{Ca}^{2+}$ pump SERCA (MIM\# 108730), and that RYR1 and STIM1 are exclusively found in the aggregate periphery (Bohm, et al. 2013). In agreement with our previous observations, the aggregates in the TAM patients with ORAII mutations also contain SERCA, and RYR1 is mainly found in the periphery of the aggregates (Figure 1). The aggregates display strong STIM1 signals, thereby linking STIM1 and ORAI1-related TAM. Of note, STIM1 signals are not restricted to the aggregate periphery; this is in contrast to the immunolocalization experiments in STIMI patients, and might reflect different ways of tubular aggregate formation in patients with STIMI or ORAI1 mutation. Aggregated ORAI1 is barely or not detectable on the biopsies of the analyzed patients, supporting the idea that tubular aggregates essentially consist of sarcoplasmic reticulum membrane and proteins.

\section{ORAI1 mutants traffic normally to plasma membrane clusters}


In order to assess the impact of the three ORAII mutations on channel localization and trafficking, we generated wild type (WT) and ORAI1-eGFP G98S, V107M, and T184M constructs, exogenously co-expressed them with human STIM1 in HEK-293T cells, and imaged the formation of ORAI1 clusters at the PM by total internal reflection fluorescence (TIRF) microscopy. WT and mutant ORAI1 were homogenously distributed in the TIRF plane in resting cells, and accumulated in clusters following depletion of $\mathrm{ER}^{\mathrm{Ca}^{2+}}$ stores with the SERCA inhibitor Thapsigargin (Tg) (Figure 3A). The intensity of the clusters and the extent of cell membrane covered by clusters was comparable in cells expressing WT or mutant ORAI1 at resting or activated state (Figure 3B and 3C). We therefore conclude that the mutations do not significantly alter the ORAI1 localization at the plasma membrane, nor its clustering upon SOCE activation.

\section{ORAII mutations produce constitutively active channels}

To evaluate the impact of the ORAII mutations on the basal channel activity, we measured the cytosolic $\mathrm{Ca}^{2+}$ levels $\left(\left[\mathrm{Ca}^{2+}\right]_{\text {cyt }}\right)$ in HEK-293T cells transfected with the ORAI1-eGFP constructs, and loaded with the ratiometric $\mathrm{Ca}^{2+}$ sensor Fura-2, AM. Cells were sequentially exposed to $\mathrm{Ca}^{2+}$-rich and $\mathrm{Ca}^{2+}$-poor media to assess the extent of $\mathrm{Ca}^{2+}$ entry across the channel in cells with replete stores (Figures 4A-C). Mean basal Fura-2 ratio values were elevated in cells expressing ORAI1 V107M $(0.52, \mathrm{SD} \pm 0.14)$ or T184M $(0.48, \mathrm{SD} \pm 0.10)$ compared to cells expressing WT ORAI1 $(0.39, \mathrm{SD} \pm 0.08)$, and decreased significantly upon $\mathrm{Ca}^{2+}$ removal. HEK-293T cells expressing the ORAI1 G98S construct displayed extremely high $\left[\mathrm{Ca}^{2+}\right]_{\text {cyt }}$ in $\mathrm{Ca}^{2+}$-rich conditions and were cultured in $0.2 \mathrm{mM} \mathrm{CaCl}$ to minimize cytotoxicity. Under these conditions, mean basal Fura-2 ratio was significantly elevated (0.68, $\mathrm{SD} \pm 0.19$, compared to WT $0.35, \mathrm{SD} \pm 0.03)$, decreased upon $\mathrm{Ca}^{2+}$ removal, and markedly increased upon addition of $2 \mathrm{mM} \mathrm{Ca}^{2+}(1.28, \mathrm{SD} \pm 0.20$, compared to WT 0.36 , SD 
\pm 0.04 , Figures $4 \mathrm{~B}$ and $4 \mathrm{C}$ ). These results suggest that the mutated ORAI1 channels are $\mathrm{Ca}^{2+}$ permeable even in the absence of store depletion, with a more pronounced degree of permeability for G98S compared to V107M or T184M ORAI1.

\section{G98S and V107M alter ORAI1 activity independently of STIM1}

In order to assess the STIM-dependence of the constitutive activation of mutant ORAI1 channels, we next transfected mouse embryonic fibroblasts bearing a targeted disruption in the Stim1 and Stim2 genes (MEF-DKO). Since steady-state $\left[\mathrm{Ca}^{2+}\right]_{\mathrm{cyt}}$ reflects the combined activity of $\mathrm{Ca}^{2+}$ pumps, channels and exchangers, we used the $\mathrm{Mn}^{2+}$ quench assay (Figures 4D-F). $\mathrm{Mn}^{2+}$ permeates through $\mathrm{Ca}^{2+}$ channels and quenches the Fura-2 fluorescence, thereby allowing the individual quantification of the influx component. In these experiments, we observed a massive $\mathrm{Mn}^{2+}$ influx in MEF-DKO cells expressing ORAI1-eGFP V107M or G98S, while only a small $\mathrm{Mn}^{2+}$ influx was detectable in cells expressing ORAI1-eGFP T184M or WT, with no significant difference among these two conditions. Similar results were obtained by measuring the amplitude of the $\mathrm{Ca}^{2+}$ elevation evoked by the readmission of $2 \mathrm{mM} \mathrm{Ca}^{2+}$ to MEF-DKO cells treated with $\mathrm{Tg}$ (Supp. Figure S2), where Fura-2 ratio increase was observed only in cells expressing G98S or V107M ORAI1. In conclusion, G98S and V107, but not T184M ORAI1 channels appear constitutively active in the absence of

STIM proteins. Accordingly, $\mathrm{Mn}^{2+}$ quench experiments in HEK-293T cells endogenously expressing STIM1 and STIM2 demonstrated that cells transfected with any of the mutant channels including ORAI1-T184M displayed significant cation entry (Supp. Figure S3).

\section{The ORAI1 mutants mediate excessive $\mathrm{Ca}^{2+}$ entry when gated by STIM1}

To test whether the ORAII mutations also impact on the STIM1-gated maximal channel activity, we co-transfected HEK-293T cells with mCherry-STIM1 and WT or mutated 
ORAI1-eGFP constructs. We induced passive reticular $\mathrm{Ca}^{2+}$ depletion through $\mathrm{Tg}$ treatment in $\mathrm{Ca}^{2+}$-free medium, and measured SOCE upon readmission of $0.5 \mathrm{mM} \mathrm{Ca}^{2+}$ to the medium. Cells expressing any of the ORAI1 mutants displayed significantly increased SOCE with 2-3 fold steeper slope of Fura-2 ratio increase compared to cells expressing WT ORAI1 (Figures

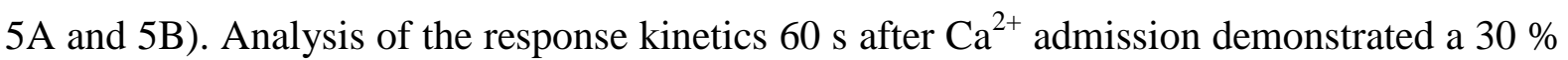
Fura-2 ratio decrease for cells transfected with WT or T184M ORAI1, while the ratio remained at near maximal levels in cells expressing G98S or V107M ORAI1 (Figure 5C).

To specifically assign ORAI1 channel activation to STIM1, we repeated the co-expression experiments in MEF-DKO cells (Figures 5D-F). Following Tg treatment and readmission of $\mathrm{Ca}^{2+}$, cells co-expressing STIM1 and V107M or T184M ORAI1 mutants displayed a strongly increased SOCE slope compared to cells co-expressing STIM1 and WT ORAI1. Expression of a control vector did not affect the $\mathrm{Ca}^{2+}$ response of the recipient cells, and expression of STIM1 alone fully restored SOCE in the MEF-DKO cells (Supp. Figure S2). Unexpectedly, MEF-DKO expressing STIM1 and WT or G98S ORAI1 and cultured in low $\mathrm{Ca}^{2+}$ exhibited a high SOCE slope (Figures 5D-E), potentially reflecting a specific adaptation of these cells to $\mathrm{Ca}^{2+}$ deprivation, and resulting in a more efficient activation of the SOCE pathway. However, and in agreement with the results obtained in transfected HEK-293T cells, the Fura-2 ratio remained elevated $60 \mathrm{~s}$ post $\mathrm{Ca}^{2+}$ readmission in cells expressing the G98S and V107M mutants while the ratio decreased in cells expressing T184M ORAI1 (Figure 5F).

Overall and in accordance with the $\mathrm{Mn}^{2+}$ quenching data, these results strongly indicate a mutation-dependent pathomechanism. All three ORAI1 mutations G98S, V107M, and T184M involve maximal SOCE in presence of active STIM1, but only G98S and V107M generate a constant $\mathrm{Ca}^{2+}$ influx independently of STIM1 activation. 


\section{DISCUSSION}

Here we report three ORAII mutations causing tubular aggregate myopathy, and we support our findings by clinical, histological, genetic and functional data. Our patients presented with different age of onset, disease severity, and additional non-muscular features, suggesting that TAM and Stormorken syndrome are spectra of the same disease. We functionally demonstrate for the first time that the mutations in different ORAI1 transmembrane domains appear to involve different pathomechanisms, and thereby uncover a genotype-phenotype correlation.

\section{Tubular aggregates in ORAI1 patients contain STIM1}

As both STIM1 and ORAII mutations lead to TAM, we compared the structure and composition of the tubular aggregates in our ORAII patients with the published STIMI patients (Bohm, et al. 2013). The tubular aggregates in STIM1 patients were shown to contain diverse sarcoplasmic reticulum proteins as RYR1, triadin, SERCA, and STIM1, and STIM1 was mainly found in the periphery of the aggregates (Bohm, et al. 2013). Immunohistofluorescence on muscle sections from ORAII patients also demonstrated the presence of STIM1 and other sarcoplasmic reticulum proteins in the aggregates. This observation provides a link between STIMI and ORAI1-related TAM at the histopathological level, and suggests that secondary STIM1 aggregation plays a role in the pathogenesis of ORAI1 mutations. Of note, the STIM1 signals were detectable in the periphery as well as in the center of the aggregates, potentially reflecting a difference in tubular aggregate formation in patients with STIMI and ORAII mutation. Even if mutated, the plasma membrane $\mathrm{Ca}^{2+}$ channel ORAI1 is barely or not detectable in the aggregates, confirming that the tubular aggregates are primarily of sarcoplasmic reticulum origin. Considering the increased $\mathrm{Ca}^{2+}$ entry resulting from STIMI or ORAII mutations, we might speculate that the excessive 
cellular $\mathrm{Ca}^{2+}$ is in large parts stored in the reticulum, provoking reticular overload and dilatation, and resulting in cisternal pinching off to form the primary stage of the tubular aggregates. This is line with the observation that tubular aggregates contain large amounts of $\mathrm{Ca}^{2+}$ (Salviati, et al. 1985; Chevessier, et al. 2005).

\section{ORAI1 mutations involve different pathomechanisms}

To mechanistically investigate the impact of the ORAI1 G98S, V107M, and T184M mutations, we analyzed the channel activity in presence or absence of STIM1. Expression of any of the mutant ORAI1-eGFP constructs in HEK-293T cells resulted in elevated basal $\mathrm{Ca}^{2+}$ levels, but in mouse fibroblasts devoid of STIM (Stim $1^{-/} /$Stim $^{--}$), only G98S and V107M induced significant cation influx in the $\mathrm{Mn}^{2+}$ quench assay. This demonstrates that both G98S and V107M ORAI1 channels are constantly permeable for $\mathrm{Ca}^{2+}$, while the overactivity of the T184M ORAI1 channel is conditioned by the presence of STIM. Accordingly, and considering that the constant fluctuation of $\mathrm{Ca}^{2+}$ levels within cellular compartments results in a varying sub-pool of activated STIM1/STIM2, and that STIM2 with is lower $\mathrm{Ca}^{2+}$ affinity and higher lipid-binding avidity has been shown to be pre-recruited to the cortical ER at basal ER $\mathrm{Ca}^{2+}$ concentrations (Parvez, et al. 2008), the endogenous STIM proteins in HEK-293T cells might be sufficient to partially activate the T184M ORAI1 channel. It is possible that the T184M mutation increases the binding sensitivity of the channel to STIM1 and STIM2 or to the transient receptor potential canonical (TRPC) channels to form a ternary complex with STIM1 at the plasma membrane (Lu, et al. 2010), which might explain the higher basal $\mathrm{Ca}^{2+}$ level in cells expressing the $\mathrm{T} 184 \mathrm{M}$ mutant even in the absence of store depletion. The extensive characterization of the T184M mutation might reveal a residue or domain

regulating STIM-mediated channel gating. Excessive $\mathrm{Ca}^{2+}$ entry was also reported for other 
ORAII mutations (Nesin, et al. 2014; Endo, et al. 2015), but the STIM-dependence of the channel activation was not investigated in these studies.

Further evidence for a different pathomechanism of the ORAII mutations comes from the coexpression experiments. HEK-293T or MEF-DKO cells co-expressing mCherry-STIM1 and any of the ORAI1-eGFP mutants induced excessive $\mathrm{Ca}^{2+}$ influx following SOCE activation, but only G98S and V107M generated a continuous and long lasting $\mathrm{Ca}^{2+}$ influx. In contrast, $\mathrm{Ca}^{2+}$ influx significantly decreased over time in HEK-293T or MEF-DKO cells co-expressing STIM1 and T184M ORAI1. This discrepancy potentially reflects a difference in $\mathrm{Ca}^{2+}$ dependent inactivation (CDI) of the mutant channels and/or their dissociation kinetics from STIM1. Alternatively, the higher basal $\mathrm{Ca}^{2+}$ levels in cells expressing ORAI1 G98S or V107M might increase the threshold triggering CDI or $\mathrm{Ca}^{2+}$ extrusion. It is also possible that the G98S and V107M mutations directly or indirectly impact on the $\mathrm{Ca}^{2+}$ extrusion systems.

In summary, our results suggest a mutation-specific pathomechanism. G98S and V107M induce constitutive channel opening independently of STIM, while T184M overactivation is conditioned by the presence of STIM. In accordance, the amino acid G98 resides in the hydrophobic gating hinge, and V107 locates near the $\mathrm{Ca}^{2+}$ selectivity filter of the M1 transmembrane domain (Zhou, et al. 2010; Hou, et al. 2012). Disturbance of these key functions is expected to impact on ion flow, which is confirmed by our functional data demonstrating constitutive $\mathrm{Ca}^{2+}$ permeability independently of STIM. This conclusion is also sustained by similar findings based on the functional characterization of artificial M1 mutations (Zhang, et al. 2011). Conversely, T184 is not located in the channel pore, and the STIM-dependent overactivation of the mutant channel strongly suggests that transmembrane domain M3 is directly or indirectly implicated in STIM-mediated ORAI1 gating.

\section{ORAI1 mutations in M1 induce a more severe phenotype}


Considering the clinical presentation of our and all previously published patients with activating ORAI1 mutations (Nesin, et al. 2014; Endo, et al. 2015), the most severe muscle phenotypes result from mutations in $\mathrm{M} 1$, a moderate muscle phenotype from a mutation in M2, and milder muscle phenotypes from mutations in M3 and M4. This correlates well with our functional data, demonstrating a stronger impact of M1 mutations on channel function.

Our patients were diagnosed with tubular aggregate myopathy based on biochemical blood tests and histological findings. All displayed repeatedly elevated serum CK levels in combination with prominent tubular aggregates as the major structural aberration on muscle biopsies. The clinical presentation was however variable, ranging from severe early-onset muscle weakness and contractures (patient 11200 from Family 1) to mild late-onset muscle weakness (patient 5510 from Family 3). A similar interfamilial variability was recently described for other families with ORAII mutations. G98S was described in two Japanese family presenting childhood-onset TAM, joint contractures, hypocalcaemia, rigid spine, and elevated CK levels (Endo, et al. 2015). We identified the same mutation in our unrelated Family 1, and the clinical manifestations were comparable. The same study reported a third Japanese family harboring the ORAII L138F mutation, and presenting with weaker clinical features involving adolescence-onset TAM, minor joint contractures, and slightly elevated CK levels. In addition, a family carrying the ORAI1 P245L mutation was described with lateonset TAM and increased CK levels (Nesin, et al. 2014).

Taking into account the clinical manifestation of all TAM patients with ORAII mutation, our functional data, and the published ORAI1 protein structure, we conclude that mutations affecting the pore lead to constitutive channel permeability, and result in early-onset muscle weakness often associated with contractures. In contrast, mutations affecting the concentric 
channel rings involve a STIM-dependent overactivity of ORAI1, and result in less severe symptoms with minor muscle weakness.

\section{ORAII patients present discrete signs of Stormorken syndrome}

Tubular aggregate myopathy in combination with miosis, thrombocytopenia, asplenia, ichthyosis, dyslexia/intellectual disability, and short stature defines Stormorken syndrome. Both TAM and Stormorken syndrome are caused by gain-of-function mutations in STIM1 and ORAI1 (Bohm, et al. 2013; Misceo, et al. 2014; Morin, et al. 2014; Nesin, et al. 2014; Endo, et al. 2015). To explore the possibilities that TAM and Stormorken syndrome are either different nosological entities or spectra of the same disease, we examined our patients for non-muscle phenotypes and reviewed the published ORAII cases. We noticed miosis (patient 11200, Family 1, and (Nesin, et al. 2014)), frequent episodes of bleeding (patient 11200, Family 1), ichthyosis, (patient 11200, Family 1), and dyslexia/intellectual disability (patients IV.1, and IV.2, Family 2, Family A (Endo, et al. 2015)). These data show that signs of Stormorken syndrome are found in many patients with activating ORAII mutations, and we conclude that TAM and Stormorken syndrome are spectra of the same disease. This is of high importance for genetic diagnosis and counseling, as ORAII mutations should be considered in patients with elevated CK levels and prominent tubular aggregates on muscle biopsies, especially if they present signs of Stormorken syndrome.

\section{Overactive SOCE versus underactive SOCE in Mendelian disorders}

STIM1 and ORAI1 act within the same SOCE pathway regulating $\mathrm{Ca}^{2+}$ homeostasis in various tissues. The identification of gain-of-function mutations in STIM1 and ORAII represents a strong proof for the implication of aberrant SOCE in the development of 
TAM/Stormorken syndrome. This is sustained by our functional and immunolocalization studies demonstrating a pathomechanistic link between both proteins.

While heterozygous gain-of-function mutations in STIM1 or ORAII generate excessive $\mathrm{Ca}^{2+}$ influx and result in the development of TAM/Stormorken syndrome (Bohm, et al. 2013; Bohm, et al. 2014; Hedberg, et al. 2014; Misceo, et al. 2014; Morin, et al. 2014; Nesin, et al. 2014; Endo, et al. 2015; Markello, et al. 2015), homozygous loss-of-function mutations in either of the genes suppress $\mathrm{Ca}^{2+}$ influx and are associated with severe immunodeficiency (Feske, et al. 2006; McCarl, et al. 2009; Picard, et al. 2009; Byun, et al. 2010; Fuchs, et al. 2012; Lacruz and Feske 2015) (MIM\# 612782, \# 612783). We conclude that strict regulation of $\mathrm{Ca}^{2+}$ homeostasis ensures normal physiology of muscle, leucocytes, platelets, skin, and other cells and tissues, and that overactive SOCE causes tubular aggregate myopathy/Stormorken syndrome, while underactive SOCE causes immunodeficiency.

\section{Conclusions}

Our work indicates for the first time a mutation-specific pathomechanism for ORAII gain-offunction mutations, thereby uncovers a clear genotype-phenotype correlation, and improves the understanding of the pathology of TAM/Stormorken syndrome and store-operated $\mathrm{Ca}^{2+}$ entry, altered in rare and common diseases.

\section{CONFLICT OF INTEREST}

None of the authors reports conflict of interest.

\section{ACKNOWLEDGEMENTS}

This article is protected by copyright. All rights reserved. 
We thank the members of the families for their cooperation and interest in this study. We are grateful to Mai Thao Viou, Anaïs Chanut, Cyril Castelbou, Sergei Startchik, Sanjeev Bhaskar, Flavia Blasevic, Franco Salerno, and Raphaël Schneider for their valuable technical assistance, and to Maud Frieden for critical evaluation of the work and the manuscript. The EuroBioBank and Telethon Network of Genetic Biobanks (GTB12001F to MM) are gratefully acknowledged for providing biological samples. We thank Liangyi Chen (Beijing University, China) for the ORAI-eGPF construct, Richard S. Lewis (Stanford University, USA) for the STIM1-mCherry construct, and Masatsugu Oh-Hora (Tokyo Medical and Dental University, Japan) for the Stim $1^{-/} /$Stim $2^{-/-}$mouse embryonic fibroblasts

\section{AUTHOR CONTRIBUTIONS}

JB, WGN, ND, and JL designed and coordinated the study. JB, MB, JU, EM, SGW, JO, AS, CK, and WGN performed the experiments. GB, MM, WGN, MR, RV, MM, HK, TD, CGD, JN, and NBR contributed clinical samples, histological and patient data. JB, MB, ND and JL wrote the manuscript.

\section{REFERENCES}

Bohm J, Chevessier F, Koch C, Peche GA, Mora M, Morandi L, Pasanisi B, Moroni I, Tasca G, Fattori F, et al. 2014. Clinical, histological and genetic characterisation of patients with tubular aggregate myopathy caused by mutations in STIM1. J Med Genet 51:824-833. 
Bohm J, Chevessier F, Maues De Paula A, Koch C, Attarian S, Feger C, Hantai D, Laforet P, Ghorab K, Vallat JM, et al. 2013. Constitutive activation of the calcium sensor STIM1 causes tubular-aggregate myopathy. Am J Hum Genet 92:271-278.

Boncompagni S, Protasi F, Franzini-Armstrong C. 2012. Sequential stages in the agedependent gradual formation and accumulation of tubular aggregates in fast twitch muscle fibers: SERCA and calsequestrin involvement. Age (Dordr) 34:27-41.

Byun M, Abhyankar A, Lelarge V, Plancoulaine S, Palanduz A, Telhan L, Boisson B, Picard C, Dewell S, Zhao C, et al. 2010. Whole-exome sequencing-based discovery of STIM1 deficiency in a child with fatal classic Kaposi sarcoma. J Exp Med 207:2307-2312.

Cai X, Zhou Y, Nwokonko RM, Loktionova NA, Wang X, Xin P, Trebak M, Wang Y, Gill DL. 2016. The Orai1 Store-operated Calcium Channel Functions as a Hexamer. J Biol Chem. Chevessier F, Bauche-Godard S, Leroy JP, Koenig J, Paturneau-Jouas M, Eymard B, Hantai D, Verdiere-Sahuque M. 2005. The origin of tubular aggregates in human myopathies. J Pathol 207:313-323.

Endo Y, Noguchi S, Hara Y, Hayashi YK, Motomura K, Miyatake S, Murakami N, Tanaka S, Yamashita S, Kizu R, et al. 2015. Dominant mutations in ORAI1 cause tubular aggregate myopathy with hypocalcemia via constitutive activation of store-operated $\mathrm{Ca}(2)(+)$ channels. Hum Mol Genet 24:637-648.

Feske S, Gwack Y, Prakriya M, Srikanth S, Puppel SH, Tanasa B, Hogan PG, Lewis RS, Daly M, Rao A. 2006. A mutation in Orail causes immune deficiency by abrogating CRAC channel function. Nature 441:179-185.

Frischauf I, Zayats V, Deix M, Hochreiter A, Jardin I, Muik M, Lackner B, Svobodova B, Pammer T, Litvinukova M, et al. 2015. A calcium-accumulating region, CAR, in the channel Orai1 enhances $\mathrm{Ca}(2+)$ permeation and SOCE-induced gene transcription. Sci Signal 8:ra131. 
Fuchs S, Rensing-Ehl A, Speckmann C, Bengsch B, Schmitt-Graeff A, Bondzio I, MaulPavicic A, Bass T, Vraetz T, Strahm B, et al. 2012. Antiviral and regulatory T cell immunity in a patient with stromal interaction molecule 1 deficiency. J Immunol 188:1523-1533. Hedberg C, Niceta M, Fattori F, Lindvall B, Ciolfi A, D'Amico A, Tasca G, Petrini S, Tulinius M, Tartaglia M, et al. 2014. Childhood onset tubular aggregate myopathy associated with de novo STIM1 mutations. J Neurol.

Hou X, Pedi L, Diver MM, Long SB. 2012. Crystal structure of the calcium release-activated calcium channel Orai. Science 338:1308-1313.

Lacruz RS, Feske S. 2015. Diseases caused by mutations in ORAI1 and STIM1. Year in Immunology 1356:45-79.

Li H, Handsaker B, Wysoker A, Fennell T, Ruan J, Homer N, Marth G, Abecasis G, Durbin R. 2009. The Sequence Alignment/Map format and SAMtools. Bioinformatics 25:2078-2079. Lu M, Branstrom R, Berglund E, Hoog A, Bjorklund P, Westin G, Larsson C, Farnebo LO, Forsberg L. 2010. Expression and association of TRPC subtypes with Orai1 and STIM1 in human parathyroid. J Mol Endocrinol 44:285-294.

Luik RM, Wu MM, Buchanan J, Lewis RS. 2006. The elementary unit of store-operated Ca2+ entry: local activation of CRAC channels by STIM1 at ER-plasma membrane junctions. J Cell Biol 174:815-825.

Markello T, Chen D, Kwan JY, Horkayne-Szakaly I, Morrison A, Simakova O, Maric I, Lozier J, Cullinane AR, Kilo T, et al. 2015. York platelet syndrome is a CRAC channelopathy due to gain-of-function mutations in STIM1. Mol Genet Metab 114:474-482. McCarl CA, Picard C, Khalil S, Kawasaki T, Rother J, Papolos A, Kutok J, Hivroz C, Ledeist F, Plogmann K, et al. 2009. ORAI1 deficiency and lack of store-operated Ca2+ entry cause immunodeficiency, myopathy, and ectodermal dysplasia. J Allergy Clin Immunol 124:13111318 e1317. 
McNally BA, Somasundaram A, Yamashita M, Prakriya M. 2012. Gated regulation of CRAC channel ion selectivity by STIM1. Nature 482:241-245.

Misceo D, Holmgren A, Louch WE, Holme PA, Mizobuchi M, Morales RJ, De Paula AM, Stray-Pedersen A, Lyle R, Dalhus B, et al. 2014. A Dominant STIM1 Mutation Causes Stormorken Syndrome. Hum Mutat.

Morin G, Bruechle NO, Singh AR, Knopp C, Jedraszak G, Elbracht M, Bremond-Gignac D, Hartmann K, Sevestre H, Deutz P, et al. 2014. Gain-of-Function Mutation in STIM1 (P.R304W) Is Associated with Stormorken Syndrome. Hum Mutat 35:1221-1232. Muik M, Frischauf I, Derler I, Fahrner M, Bergsmann J, Eder P, Schindl R, Hesch C, Polzinger B, Fritsch R, et al. 2008. Dynamic coupling of the putative coiled-coil domain of ORAI1 with STIM1 mediates ORAI1 channel activation. J Biol Chem 283:8014-8022. Navarro-Borelly L, Somasundaram A, Yamashita M, Ren D, Miller RJ, Prakriya M. 2008. STIM1-Orai1 interactions and Orai1 conformational changes revealed by live-cell FRET microscopy. J Physiol 586:5383-5401.

Nesin V, Wiley G, Kousi M, Ong EC, Lehmann T, Nicholl DJ, Suri M, Shahrizaila N, Katsanis N, Gaffney PM, et al. 2014. Activating mutations in STIM1 and ORAI1 cause overlapping syndromes of tubular myopathy and congenital miosis. Proc Natl Acad Sci U S A.

Park CY, Hoover PJ, Mullins FM, Bachhawat P, Covington ED, Raunser S, Walz T, Garcia KC, Dolmetsch RE, Lewis RS. 2009. STIM1 clusters and activates CRAC channels via direct binding of a cytosolic domain to Orai1. Cell 136:876-890.

Parvez S, Beck A, Peinelt C, Soboloff J, Lis A, Monteilh-Zoller M, Gill DL, Fleig A, Penner R. 2008. STIM2 protein mediates distinct store-dependent and store-independent modes of CRAC channel activation. FASEB J 22:752-761. 
Picard C, McCarl CA, Papolos A, Khalil S, Luthy K, Hivroz C, LeDeist F, Rieux-Laucat F, Rechavi G, Rao A, et al. 2009. STIM1 mutation associated with a syndrome of immunodeficiency and autoimmunity. N Engl J Med 360:1971-1980.

Salviati G, Pierobon-Bormioli S, Betto R, Damiani E, Angelini C, Ringel SP, Salvatori S, Margreth A. 1985. Tubular aggregates: sarcoplasmic reticulum origin, calcium storage ability, and functional implications. Muscle Nerve 8:299-306.

Stathopulos PB, Li GY, Plevin MJ, Ames JB, Ikura M. 2006. Stored Ca2+ depletion-induced oligomerization of stromal interaction molecule 1 (STIM1) via the EF-SAM region: An initiation mechanism for capacitive Ca2+ entry. J Biol Chem 281:35855-35862.

Thompson JL, Shuttleworth TJ. 2013. How many Orai's does it take to make a CRAC channel? Sci Rep 3:1961.

Vig M, Beck A, Billingsley JM, Lis A, Parvez S, Peinelt C, Koomoa DL, Soboloff J, Gill DL, Fleig A, et al. 2006. CRACM1 multimers form the ion-selective pore of the CRAC channel. Curr Biol 16:2073-2079.

Walter MC, Rossius M, Zitzelsberger M, Vorgerd M, Muller-Felber W, Ertl-Wagner B, Zhang Y, Brinkmeier H, Senderek J, Schoser B. 2015. 50 years to diagnosis: Autosomal dominant tubular aggregate myopathy caused by a novel STIM1 mutation. Neuromuscul Disord 25:577-584.

Zhang SL, Yeromin AV, Hu J, Amcheslavsky A, Zheng H, Cahalan MD. 2011. Mutations in Orai1 transmembrane segment 1 cause STIM1-independent activation of Orai1 channels at glycine 98 and channel closure at arginine 91. Proc Natl Acad Sci U S A 108:17838-17843. Zheng H, Zhou MH, Hu C, Kuo E, Peng X, Hu J, Kuo L, Zhang SL. 2013. Differential roles of the $\mathrm{C}$ and $\mathrm{N}$ termini of Orai1 protein in interacting with stromal interaction molecule 1 (STIM1) for $\mathrm{Ca} 2+$ release-activated $\mathrm{Ca} 2+(\mathrm{CRAC})$ channel activation. J Biol Chem 288:11263-11272. 
Zhou Y, Ramachandran S, Oh-Hora M, Rao A, Hogan PG. 2010. Pore architecture of the ORAI1 store-operated calcium channel. Proc Natl Acad Sci U S A 107:4896-4901. 


\section{FIGURE LEGENDS}

Figure 1 - Histological, ultrastructural, and immunohistochemical characterization of the biopsies

(A) Muscle biopsies from patients from all three families display tubular aggregates appearing in red on Gomori trichrome and in dark blue on NADH-TR staining in both fiber types. The aggregates are barely detectable with SDH. Minor fiber size variability and internalized nuclei are also noted. Ultrastructural analyses demonstrate that the tubular aggregates are of variable size and consist of single or double-walled membranes of different diameter. EM pictures were not available for Family 2. (B) Immunolocalization studies on biopsies from Family 1 and Family 2 show that the tubular aggregates contain STIM1, RYR1, SERCA, whereas ORAI1 is barely or not trapped. Note that STIM1 signals are found in the periphery and in the center of the aggregates, while RYR1 is mainly found in the periphery (arrows). * indicate identical fibers of serial sections. 


\section{Figure 1}
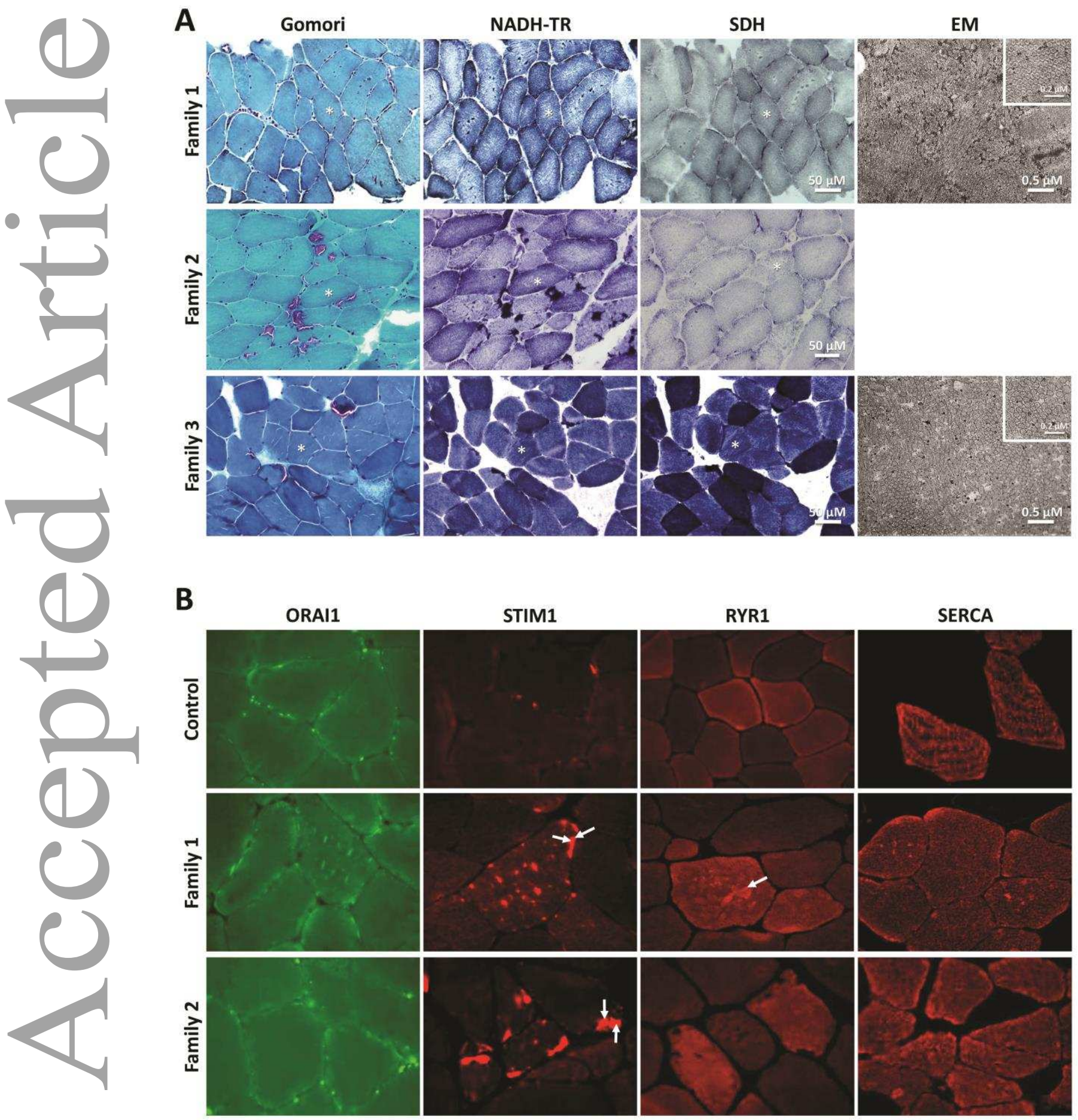

This article is protected by copyright. All rights reserved. 


\section{Figure 2 - Identification of $O R A I 1$ mutations}

(A) Heterozygous ORAII missense mutations were identified in all three families, and segregated with the disease. (B) The mutations affect highly conserved amino acids in ORAI1. (C) Schematic representation of ORAI1. Mutations found in our patients are depicted in blue, published mutations appear in red. G98S and V107M affect amino acids in transmembrane domain 1 (M1), and T84M affects an amino acid in M3. Residue G98 is located in the rigid section of the channel, and V107 neighbors the $\mathrm{Ca}^{2+}$ selectivity filter E106.

\section{Figure 2}

A

10

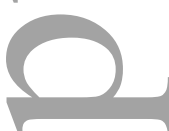

(1)

Mouse

Dog

Chicken

Xenopus

Drosophila

C.elegans
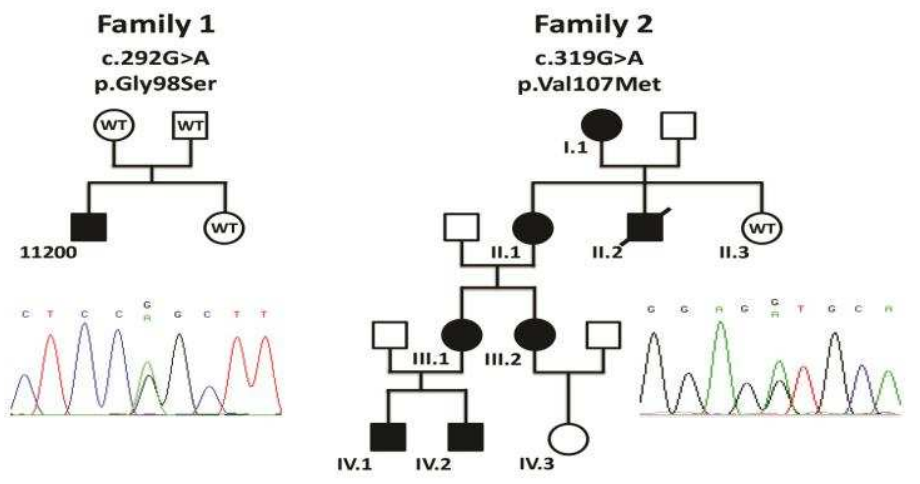

Val107Met

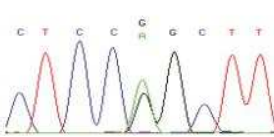

G98 V107 SALL SGF AMVAMVEVQLDADHDYPPGLLI AFSACTTVIVAVHLF ALMISTCILPNI EAVSNVHNLNSVRESPHERMHRH I ELAWAFSTVIGTLLFLAEVV SALL SGF AMVAMVEVQLDADHDYPPGLLI AFS SCT TVIVAVHLFALMISTCI LPN I EAVSNVHNLNSVKESPHERMHRH I EL AWAFSTVIGTLLFLAEVV SALL SGF AMVAMVEVQLDTDHDYPPGLLIVFSACTTVIVAVHLFALMISTCILPNI EAVSNVHNLNSVKESPHERMHRH I ELAWAFS TVI GTLLFLAEVV

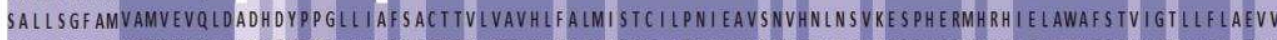

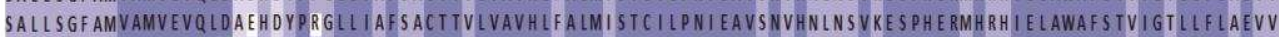
SALL SGF AMVAMVEVQLEADHAYPPGLL I AFSACT TVIVAVHLFALMI STCILPNIEAVSNVHNL NSVKESPHERMHRH IEL AWAFSTV I GTLLFLAEVV SALLSGFAMVAMVEVQLOHDTNVPPGML IAFAICTTLLIVAVHMLALMI STCILPNIETVCNLHSISLVHESPHERLHWYIETAWAFSTLLGLILFLLEIA ALLAGFAMVCLVELQYDQST PKPLLIVLGVVTSLIVSVHLLALMMSTCILPYMEAT GCTQDSPHIKLKFYIDLSWLFSTCIGLLLFLVEIG'

C

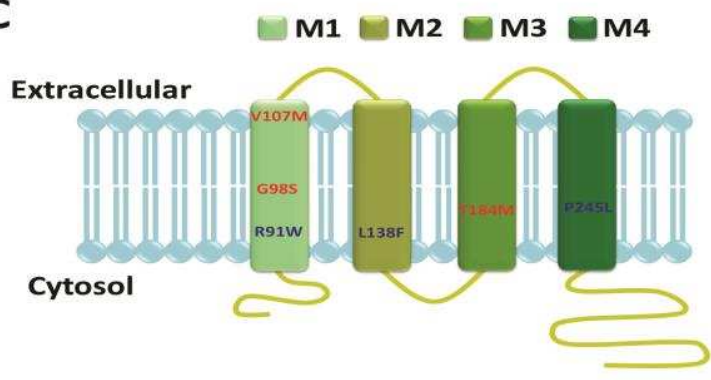

This article is protected by copyright. All rights reserved. 


\section{Figure 3 - Effect of $O R A I 1$ mutations on channel localization and clustering at the PM}

(A) TIRF images of HEK-293T co-expressing STIM1 and wild-type (WT) or mutated (V107M, T184M, G98S) ORAI1-eGFP taken before and 10 min after addition of $1 \mu \mathrm{M}$ Thapsigargin (Tg). Insets show cluster morphology at higher magnification. (B) Changes in intensity of eGFP clusters and in cluster density (\% PM covered by clusters) in the TIRF plane following Tg addition in cells co-expressing STIM1 and WT or mutated ORAI1-eGFP. (C) Statistical evaluation of eGFP cluster intensity and density before and after $\mathrm{Tg}$ treatment. Data are mean \pm SEM of $33,24,25$, and 14 cells for WT, V107M, T184M and G98S, respectively. No statistically significant differences were observed between WT and mutated channels in resting and store-depleted conditions.

\section{Figure 3}

A

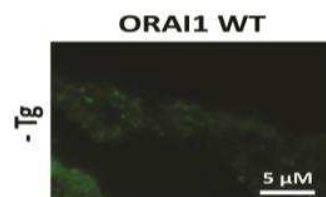

ORAI1 V107M

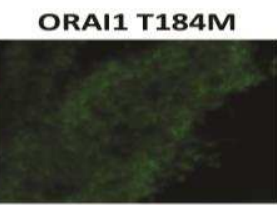

ORAI1 G98S
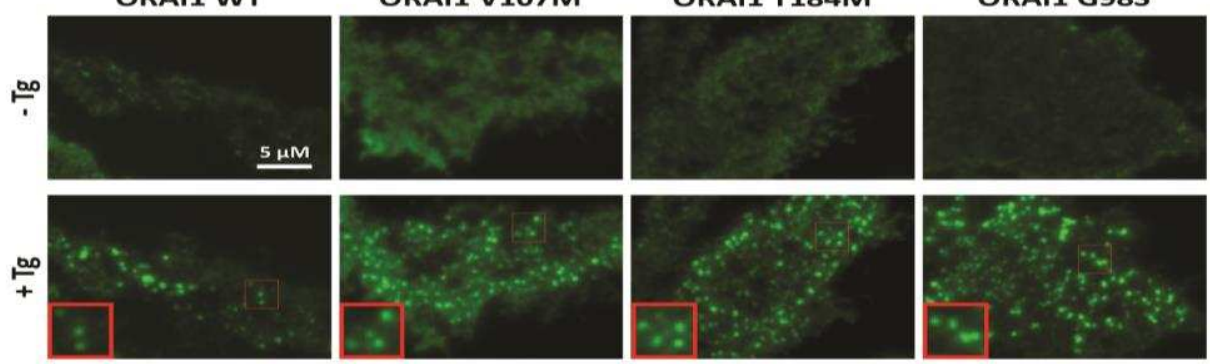

B
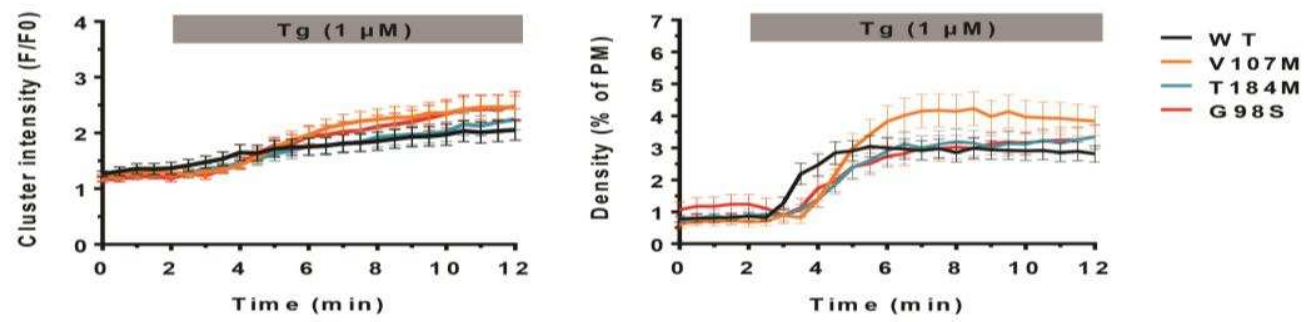

C
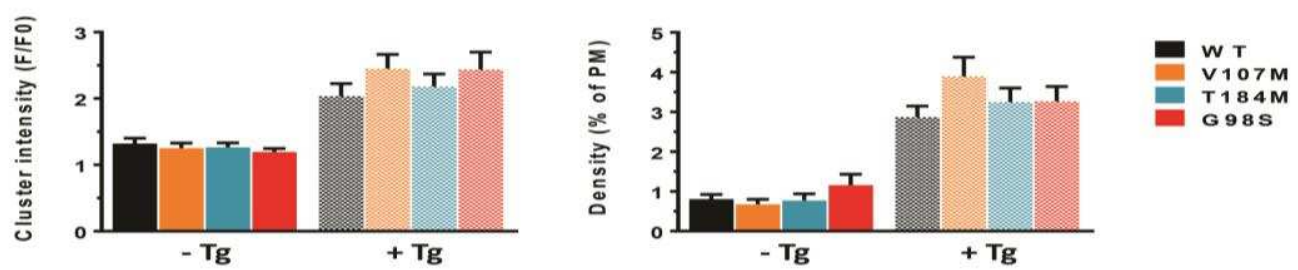

This article is protected by copyright. All rights reserved. 


\section{Figure 4 - Effect of ORAII mutations on basal $\mathrm{Ca}^{2+}$ level}

(A) Representative Fura-2 recordings of HEK-293T cells expressing wild-type (WT) or mutated (V107M, T184M) ORAI1-eGFP during $\mathrm{Ca}^{2+}$ removal $\left(2 \mathrm{mM} \mathrm{Ca}^{2+}\right.$ replaced by 1 mM EGTA). (B) Recordings of cells expressing WT or G98S ORAI1-eGFP during $\mathrm{Ca}^{2+}$ removal and readmission. Cells were cultured in $\mathrm{Ca}^{2+}$-poor medium $(0.2 \mathrm{mM})$ to mitigate the toxicity associated with the G98S mutation. (C) Statistical evaluation of the responses illustrated in (A) and (B), measured between the time points indicated with \# $(n=79,39,49$ for WT, V107M, T184M respectively, and $\mathrm{n}=38,20$ for WT and G98S cultured in low $\mathrm{Ca}^{2+}$ ). (D), (E) Representative $\mathrm{Mn}^{2+}$ quench recordings of MEF-DKO cells $\left(\right.$ Stim $1^{-/} /$Stim $^{-/}$) expressing WT or mutated ORAI1-eGFP. Fura-2 fluorescence was recorded at $360 \mathrm{~nm}$ in the presence of $2 \mathrm{mM} \mathrm{Ca}^{2+}$. Traces are offset to facilitate comparison. (F) Statistical evaluation of $\mathrm{Mn}^{2+}$ quench rates in (D) and (E), measured between the time points indicated with \# $(\mathrm{n}=17$, 20, 21 and 23, 32 for WT, V107M, T184M, and WT, G98S cultured in low $\mathrm{Ca}^{2+}$, respectively). Data are mean \pm SEM, statistically significant differences versus respective WT conditions are indicated by $* * * * \mathrm{p}<0.0001$. 
Figure 4

A

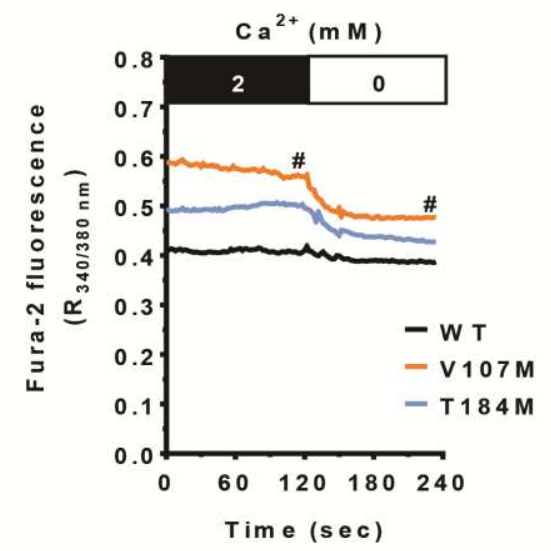

B

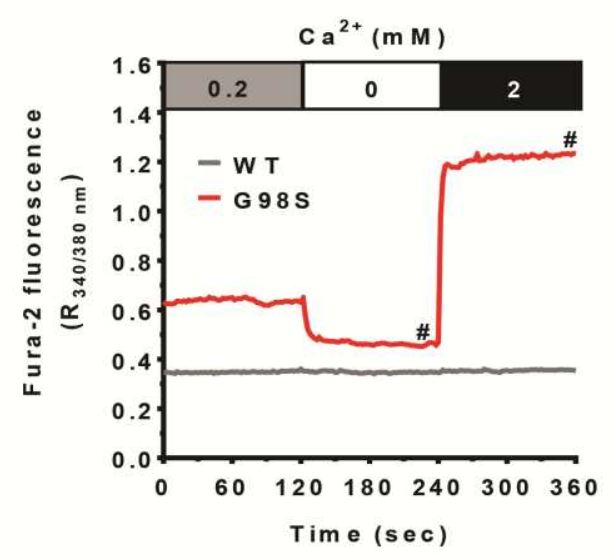

C

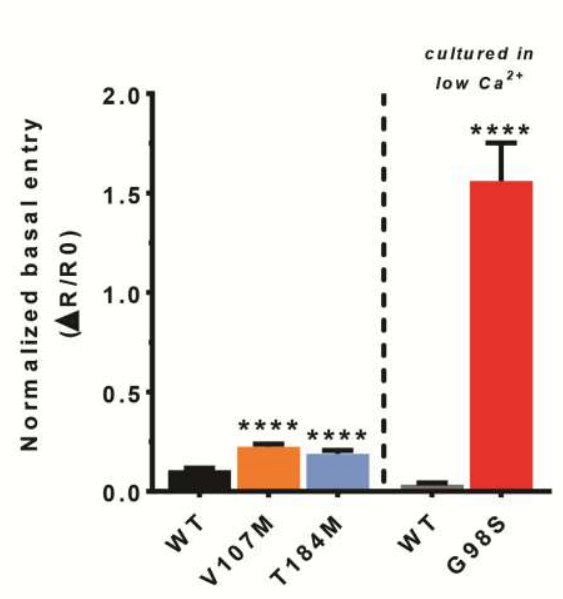

D

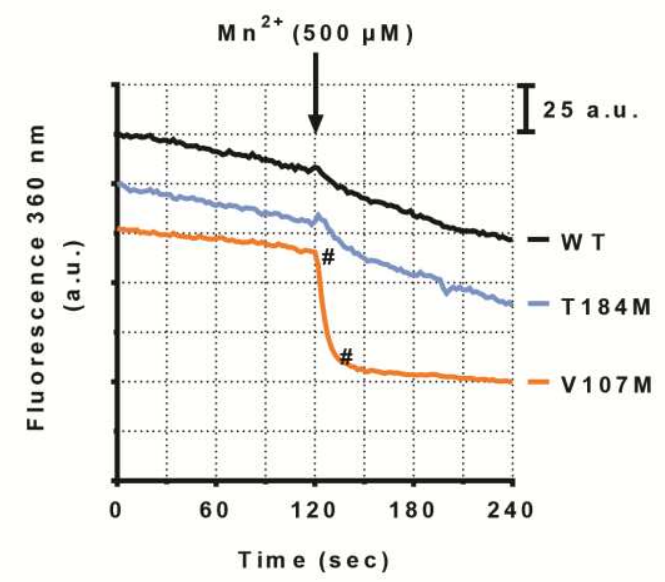

E

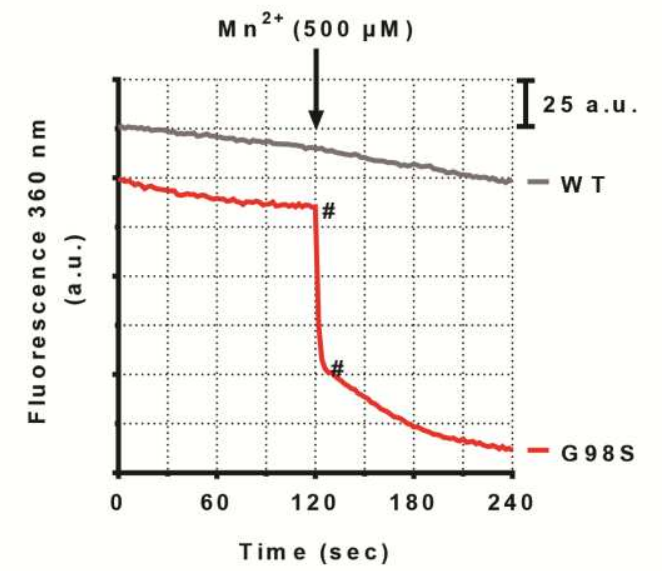

$\mathbf{F}$

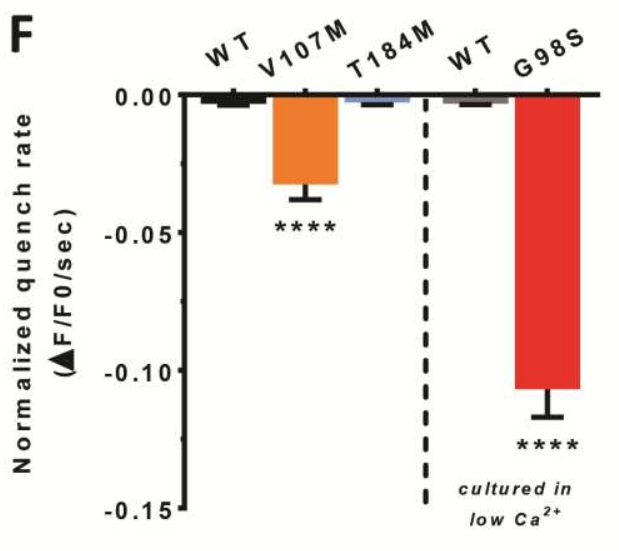




\section{Figure 5 - Effect of $O R A I 1$ mutations on maximal SOCE}

(A), (D) Fura-2 responses evoked by the readmission of $0.5 \mathrm{mM} \mathrm{Ca}^{2+}(\mathrm{HEK}-293 \mathrm{~T})$ or $2 \mathrm{mM}$ $\mathrm{Ca}^{2+}$ (MEF-DKO) to cells co-expressing mCherry-STIM1 and ORAI1-eGFP (WT, V107M, T184M or G98S) treated with Tg. (B), (E) Statistical evaluation of the influx rate evoked by $\mathrm{Ca}^{2+}$ readmission in (A) and (D), measured as the Fura-2 increase slope between the time points indicated with \#. (C), (F) Statistical evaluation of the $\mathrm{Ca}^{2+}$ level 60 seconds after the peak of the response in (A) and (D), illustrated by the dotted line, and expressed as percentage of the peak. Data are mean \pm SEM of 24-51 cells for (B), (C) and of 17-29 cells for $(\mathrm{E}),(\mathrm{F})$. Statistically significant differences versus respective WT conditions are indicated by $* * \mathrm{p}<0.01, * * * \mathrm{p}<0.001$, and $* * * * \mathrm{p}<0.0001$. 


\section{Figure 5}
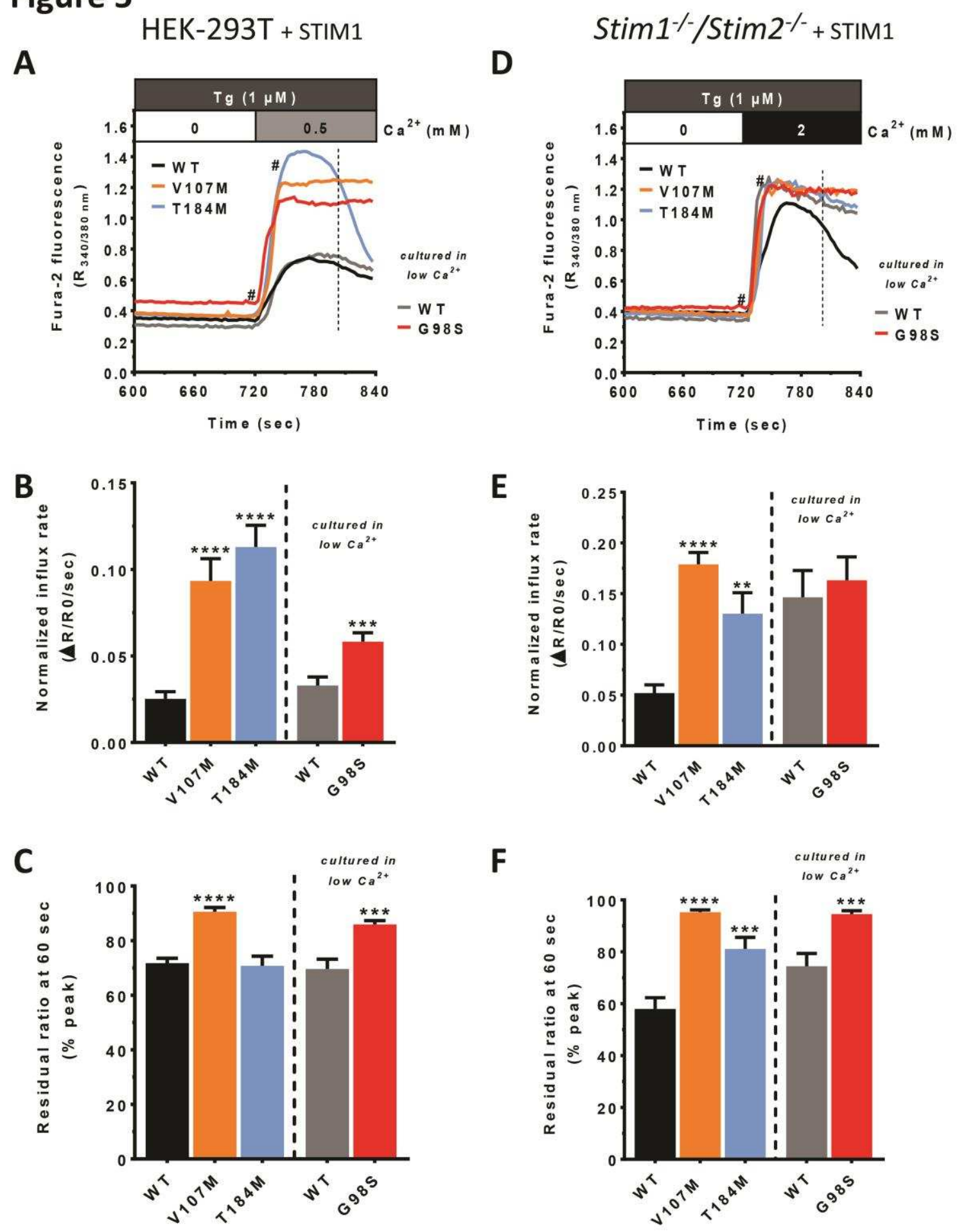

This article is protected by copyright. All rights reserved. 
Table 1. Genetic, clinical and histological features in patients with ORAI1 mutations

\begin{tabular}{|c|c|c|c|c|c|c|c|c|c|}
\hline & Family 1 & \multicolumn{7}{|c|}{ Family 2} & \multirow{2}{*}{$\begin{array}{c}\text { Family } 3 \\
5510\end{array}$} \\
\hline Individual & 11200 & I.1 & II.1 & II. 2 & III.1 & III. 2 & IV.1 & IV.2 & \\
\hline Gender & $\mathrm{M}$ & $F$ & $\mathrm{~F}$ & $\mathrm{M}$ & $\mathrm{F}$ & $F$ & $\mathrm{M}$ & $\mathrm{M}$ & $\mathrm{M}$ \\
\hline Iutation & $\begin{array}{l}\text { c. } 292 \mathrm{G}>\mathrm{A} \\
\text { p.Gly98Ser }\end{array}$ & $\begin{array}{c}\text { c.319G>A } \\
\text { p.Val107Met }\end{array}$ & $\begin{array}{c}\text { c.319G>A } \\
\text { p.Val107Met }\end{array}$ & $\begin{array}{c}\text { c.319G }>\text { A } \\
\text { p.Val107Met }\end{array}$ & $\begin{array}{c}\text { c.319G>A } \\
\text { p.Val107Met }\end{array}$ & $\begin{array}{c}\text { c.319G>A } \\
\text { p.Val107Met }\end{array}$ & $\begin{array}{c}\text { c.319G }>\text { A } \\
\text { p.Val107Met }\end{array}$ & $\begin{array}{c}\text { c.319G }>\text { A } \\
\text { p.Val107Met }\end{array}$ & $\begin{array}{c}\text { c.551C>T } \\
\text { p.Thr184Met }\end{array}$ \\
\hline Onset & childhood & unknown & childhood & unknown & childhood & childhood & childhood & childhood & adulthood \\
\hline Age at last examination & 10 & no examination & 47 & $\begin{array}{c}\text { no } \\
\text { examination }\end{array}$ & 25 & 31 & 8 & 6 & 60 \\
\hline symptoms & $\begin{array}{l}\text { proximal and distal } \\
\text { weakness of lower } \\
\text { limbs, myalgia, } \\
\text { cramps, stiffness }\end{array}$ & NA & $\begin{array}{l}\text { stiffness, } \\
\text { cramps }\end{array}$ & NA & $\begin{array}{c}\text { proximal } \\
\text { weakness of } \\
\text { lower limbs, } \\
\text { exercise-induced } \\
\text { myalgia }\end{array}$ & $\begin{array}{c}\text { weakness of } \\
\text { arms, cramps }\end{array}$ & $\begin{array}{l}\text { myalgia, } \\
\text { stiffness }\end{array}$ & myalgia & $\begin{array}{c}\text { mild general } \\
\text { weakness, myalgia } \\
\text { in lower limbs, } \\
\text { cramps }\end{array}$ \\
\hline Valking & $\begin{array}{l}\text { tip-toe walking, } \\
\text { waddling gait }\end{array}$ & NA & $\begin{array}{l}\text { tip-toe walking, } \\
\text { difficulty } \\
\text { climbing stairs }\end{array}$ & NA & $\begin{array}{l}\text { tip-toe walking, } \\
\text { difficulty } \\
\text { climbing stairs }\end{array}$ & $\begin{array}{l}\text { tip-toe } \\
\text { walking }\end{array}$ & $\begin{array}{l}\text { tip-toe } \\
\text { walking }\end{array}$ & normal & normal \\
\hline Contractures & $\begin{array}{c}\text { elbows, Achilles } \\
\text { tendons }\end{array}$ & NA & Achilles tendons & NA & Achilles tendons & NA & $\begin{array}{l}\text { Achilles } \\
\text { tendons }\end{array}$ & $\begin{array}{l}\text { Achilles } \\
\text { tendons }\end{array}$ & no \\
\hline CK level (U/I) & 2052 & NA & 791 & NA & 1383 & 597 & 1538 & 484 & 600 \\
\hline
\end{tabular}

This article has been accepted for publication and undergone full peer review but has not been through the copyediting, typesetting, pagination and proofreading process, which may lead to differences between this version and the Version of Record. Please cite this article as doi: $10.1002 /$ humu.23172.

This article is protected by copyright. All rights reserved. 


\begin{tabular}{|c|c|c|c|c|c|c|c|c|c|}
\hline normal range $60-180$ & & & & & & & & & \\
\hline Histology & $\begin{array}{l}\text { TAs in type I/II } \\
\text { fibers, fiber size } \\
\text { variability, } \\
\text { internalized nuclei }\end{array}$ & NA & $\begin{array}{l}\text { TAs in type I/II } \\
\text { fibers, fiber size } \\
\text { variability, } \\
\text { internalized } \\
\text { nuclei }\end{array}$ & NA & NA & NA & NA & NA & $\begin{array}{l}\text { TAs in type I/II } \\
\text { fibers, fiber size } \\
\text { variability, } \\
\text { internalized nuclei }\end{array}$ \\
\hline $\begin{array}{c}\text { Signs of Stormorken } \\
\text { syndrome }\end{array}$ & $\begin{array}{l}\text { ichtyosis, miosis, } \\
\text { bleeding episodes }\end{array}$ & NA & no & NA & no & no & dyslexia & dyslexia & no \\
\hline Other features & $\begin{array}{l}\text { occasional mild } \\
\text { hypocalcemia }\end{array}$ & $\begin{array}{c}\text { COPD, } \\
\text { cerebrovascular } \\
\text { disease }\end{array}$ & no & NA & calf hypertrophy & no & $\begin{array}{c}\text { calf } \\
\text { hypertrophy, } \\
\text { seizures }\end{array}$ & $\begin{array}{c}\text { calf } \\
\text { hypertrophy, } \\
\text { scapular } \\
\text { winging }\end{array}$ & $\begin{array}{c}\text { hypereosinophilia, } \\
\text { pectus excavatum, } \\
\text { arched palate }\end{array}$ \\
\hline
\end{tabular}

$\mathrm{NA}=$ not assessed

This article is protected by copyright. All rights reserved. 